\title{
Asian Dust properties investigated by multi-instruments
}

\author{
Janbai Nee* \\ National Central University, Department of Physics, Chungli, Taiwan 32001
}

\begin{abstract}
Dust and many types of aerosols are major pollutants significantly affecting the environment in the East Asia. To identify and classify various types of aerosols is a challenge. In Taiwan and nearby areas, Asian Dust mainly arrive in spring with an average of about 5 dust storms each year. They usually come with some other aerosol sources, therefore it is important to identify these aerosols and their properties. In this paper, we report studying of dust aerosols by using several ground-based and remote sensing measurements. The AERONET data is used to find optical properties of aerosols in 2008-2012. The lidar observations can investigate further properties and atmospheric processes for specific dust events, including observations of aerosol-cloud interactions. These combined with model or space observations can help us to understand long range dust particles transported to distant areas and their interaction with weather systems. A real time case of observation of dust-cloud interaction is provided.
\end{abstract}

\section{Introduction}

Asian Dust (AD) is a major environmental concern in the spring and late winter in Taiwan and many cities of the East Asia. Every year in Taiwan there are about 5 cases of AD. However, the year 2009 has recorded the most numbers of AD cases ( 9 cases) and with a case of severest $\mathrm{AD}$ event over 20 years in history. We report in this paper investigation of dust events and their properties based on several types of measurements from the ground and space.

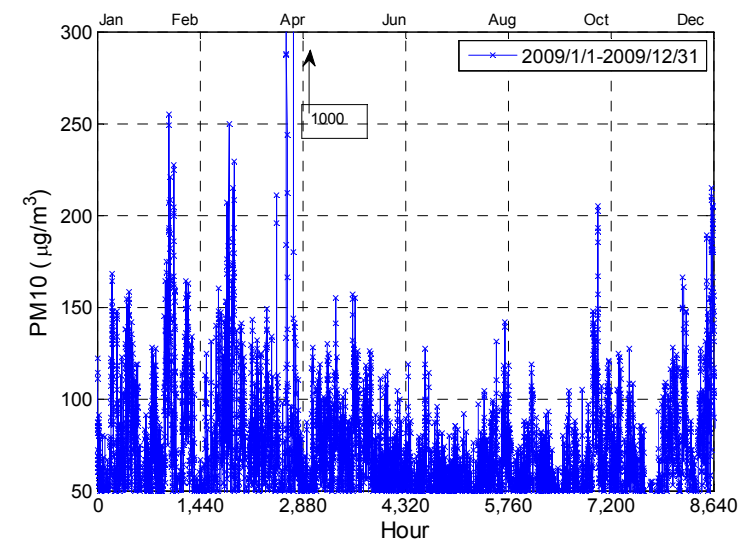

Figure 1. The hourly PM10 $\left(\mu \mathrm{g} / \mathrm{m}^{3}\right)$ recorded in the city Chungli in 2009.

Figure 1 shows the hourly ground PM10 data in 2009 in Chungli city $\left(25^{\circ} \mathrm{N}, 121^{\circ} \mathrm{E}\right)$ from which we can find PM10 are higher in spring and late winter where several high PM10 events above $200 \mu \mathrm{g} / \mathrm{m}^{3}$ were recorded. The highest event with PM10 about $1000 \mu \mathrm{g} / \mathrm{m}^{3}$ occurred on 25 April. The types of aerosols include AD, biomass aerosols from Southeast Asia, local pollution, sea salt and pollution from other regions. To identify various aerosol sources and properties is the first thing to do for environmental protection. In this paper, we would like to report studies by using various techniques.

Ground-based PM10 measurement is an important reference for understanding the pollution events, but not enough to identify the pollution types and sources. Recently, techniques of analyzing aerosol properties by using the AERONET sun photometer data have shown progress in identifying aerosol properties. The AERONET measurements are made of observing the solar radiation at wavelengths typically $340,440,500$, $670,870,1020 \mathrm{~nm}$ from ground. From these measurements, we can derive parameters such as the optical thickness (AOD), Ångström Exponent (AE), single scattering albedo (SSA), and many other parameters [1-4]. Further analyses can be made to distinguish the scattering and absorption parts of these variables. The AAOD (absorption AOD), and SAOD (scattering AOD) are defined by using the definition of $\mathrm{SSA}$ as $\mathrm{AAOD}=\mathrm{AOD} \cdot(1-\mathrm{SSA})$ and $\mathrm{SAOD}=\mathrm{AOD} \cdot \mathrm{SSA}$. The AAE (absorption AE) and SAE (scattering AE) are defined by using AAOD and SAOD as:

$$
\mathrm{AAE}=\left[\operatorname { l o g } \left(\operatorname{AAOD}\left(\lambda_{1}\right) /\left(\operatorname{AAOD}\left(\lambda_{2}\right)\right] / \log \left(\lambda_{2} / \lambda_{1}\right)\right.\right.
$$

and similarly SAE but using SAOD instead. Here the wavelengths, $\lambda_{1}$ and $\lambda_{2}$ are 440 and $870 \mathrm{~nm}$ respectively. Studies have shown aerosols can be separated into several major types as urban-industrial, biomass burning, mineral dust, maritime by using parameters including AAOD AAE, SAE, and SSA, in which the absorption parameters are related with chemical properties and scattering parameters for physical parameters such as particle size or shape factor [1-4]. AERONET at National Central University (NCU) site (Chungli city,

\footnotetext{
* Corresponding author: jbnee@phy.ncu.edu.tw
} 
$25^{\circ} \mathrm{N}, 121^{\circ} \mathrm{E}$ ) has a long history of records and can be used to derive parameters of AAOD, AAE, SSA etc. for the time period 2008-2012. Since sun photometer works only under no cloud condition, data of extended years are needed to cover all seasons. We will first show AERONET measurements for understanding aerosols below.

\section{Optical properties of aerosols by AERONET}

Figure 2 are plots by using AE (440/870 nm), SSA, and AAE. From Fig. (2a), we find aerosols are roughtly separated into two groups: urban pollution and polluted dust. It is not surprising since dust particles arrived here by transporting through vast areas of urban and industrial regions across the mainland China. They interact with pollution to acquire varied surface coatings of nitrate, surfate, ammonium, and other compounds [5-6]. Figure (2b) shows the distribution of $\operatorname{SSA}(440 \mathrm{~nm})$ on different days of the 4 years (days of year for each year). For non-absorbing aerosol, SSA has a value about 1 and for polluted aerosol SSA is less than 1 [1-2]. From Fig. (2b), we find lower values of SSA are located in the spring time and winter time, with SSA 0.93. The chemical properties of aerosols are also characterized by the Absorption AE (AAE) which has an average value of 1.335 which again is attributed to polluted aerosols as shown in Fig. (2c). The distribution of AAE is shown in Fig. (2d), which fit mostly to polluted aerosols.

\section{Lidar measurement of the long-range transported dust}

AERONET data are integrated measurements throughout the atmosphere, which alone are not enough to identify all physical and optical properties of aerosols. As we will see, air at different heights may have different sources. The lidar vertical profiles can be further analyzed to study aerosol properties and sources. The ground based lidar measurements are normally made by using a laser of $532 \mathrm{~nm}$ wavelength and detecting the returning signals of two components of polarizations through a system of PMTs, filters, and telescope as shown in previous papers [7-8]. Figure 3 shows a dust event on 15 January 2009 where layers of aerosols are found at 0.5-2.5 $\mathrm{km}$. Based on the height data, the HYSPLIT back-trajectory calculations are carried out (Fig. 3c). We find the lower air below $1 \mathrm{~km}$ can be traced to Mongolia, likely the Gobi Desert, while the upper air above $2 \mathrm{~km}$ may be traced to the Western China in the region of Taklamakan desert. Therefore, dust particles may come from two different deserts.

From the back-trajectories, we can see arctic air passing through desert region bringing the dust up to heights above $6000 \mathrm{~m}$ and then move to the south in two or three days to reach the coastal areas in the lower atmosphere $(500 \mathrm{~m})$ so that dust particles can have ample chances of interaction with pollution and clouds while traveling through the continent.
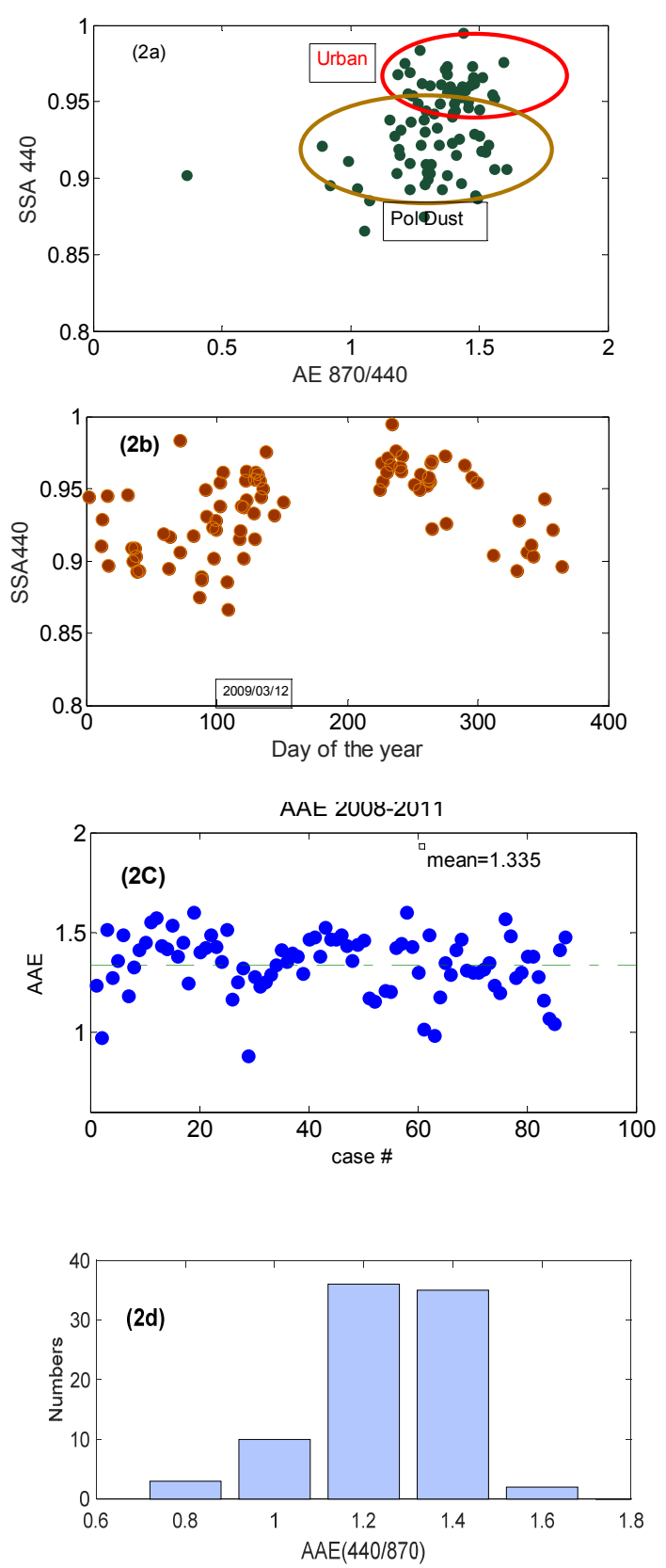

Figure 2. AERONET parameters of 2008-2011: (2a) SSA440 versus AE440/870, (2b) Distribution of SSA440 as days of the year for 2008-2011, (3c) variation of AAE, (3d) plots of AAE $440 / 870$ for number of cases in 2008-2011.

On 25 April 2009, a major dust storm arrived in Taiwan with ground PM10 1000 $\mu \mathrm{g} / \mathrm{m}^{3}$ measured over almost all cities. It was the heaviest dust storm in 20 years. Lidar measurements from the ground and space (CALIPSO, Cloud-Aerosol Lidar and Infrared Pathfinder Satellite Observations) showed layers at about $2 \mathrm{~km}$ in the northeast as shown in Fig. 4. Based on backtrajectory analysis, we found there were two different sources as shown in Fig. 5. The lower air can be traced to the Gobi area while the upper air $(2.5 \mathrm{~km})$ was traced to Southeast Asia regions. In the spring, burning of farm products is practiced by farmers in Southeast Asia, which becomes a major source of pollution later transported to distant regions. 

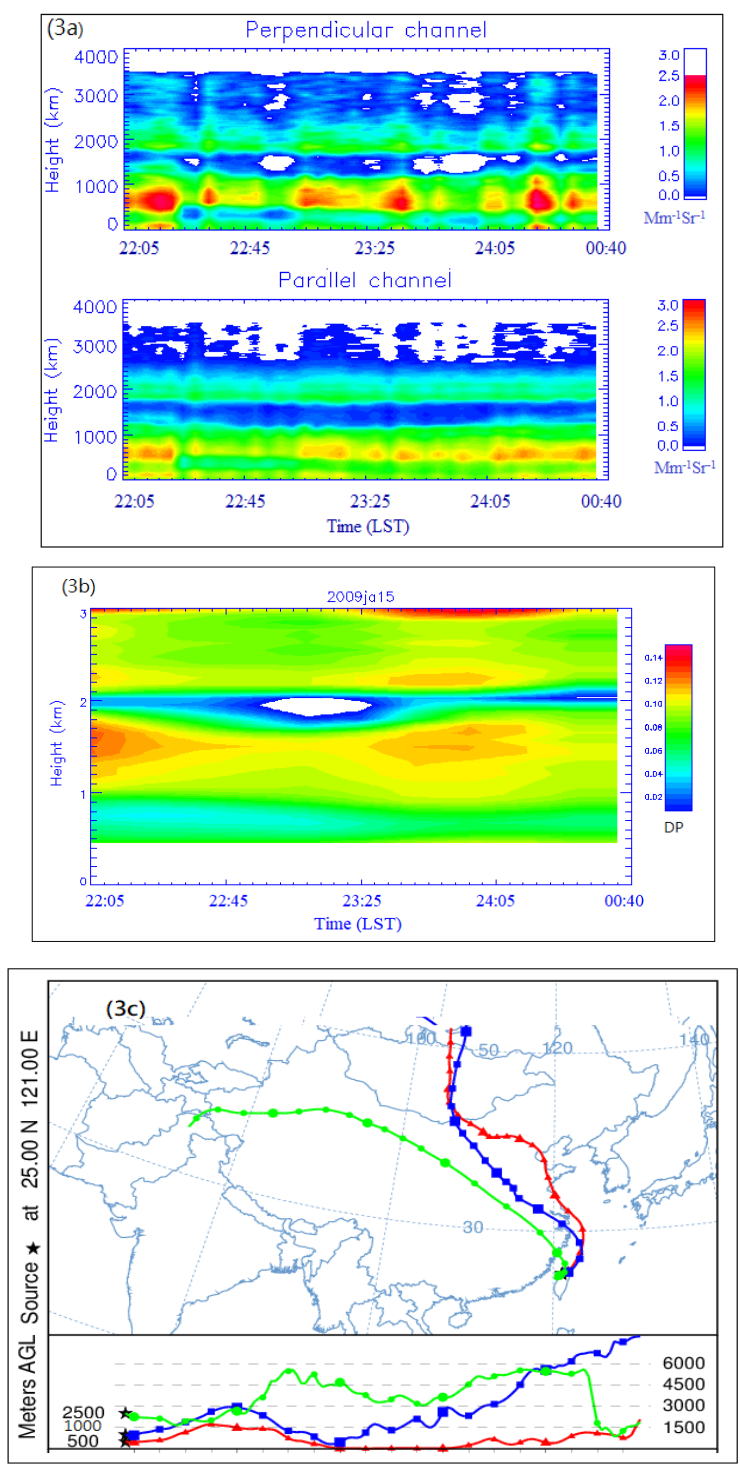

Figure 3. Dust cases of 15 January 2009: (3a) The backscattering coefficient in $\left(\mathrm{Mm}^{-1} \mathrm{sr}^{-1}\right)$ in perpendicular (top) and parallel channels (bottom), (3b) the depolarization ratio (DP) with peak about $0.1,(3 \mathrm{c})$ the backtrajectories of aerosols at 500, 1000, and $2500 \mathrm{~m}$ ending 0200 UTC 15 Jan.

\section{Interaction of dust, ambient air and clouds}

Previous sections have shown long-range transported dust became polluted particles. In Taiwan area, dust storms are often accompanied by occurring of precipitation producing yellow rain sometimes. The interaction of dust and cloud is an important subject to understand in climate change yet not well understood. Studies in Mideast [9] and Japan [10-12] have found dust particles transformed into liquid droplets following interaction with humidity because of heterogeneous reactions of $\mathrm{Ca}^{+}$in the dust, which reacts with $\mathrm{HNO}_{3}$ and $\mathrm{HCl}$ in the air [9-10]. Calcium compounds are a dominant composition of $\mathrm{AD}$ and are highly hygroscopic. Li and Osada [11] also observed the morphological change of AD. They found dust particles become essentially spherical with median circularity factor about 0.9 in Japan but are less than 0.8 in source regions.
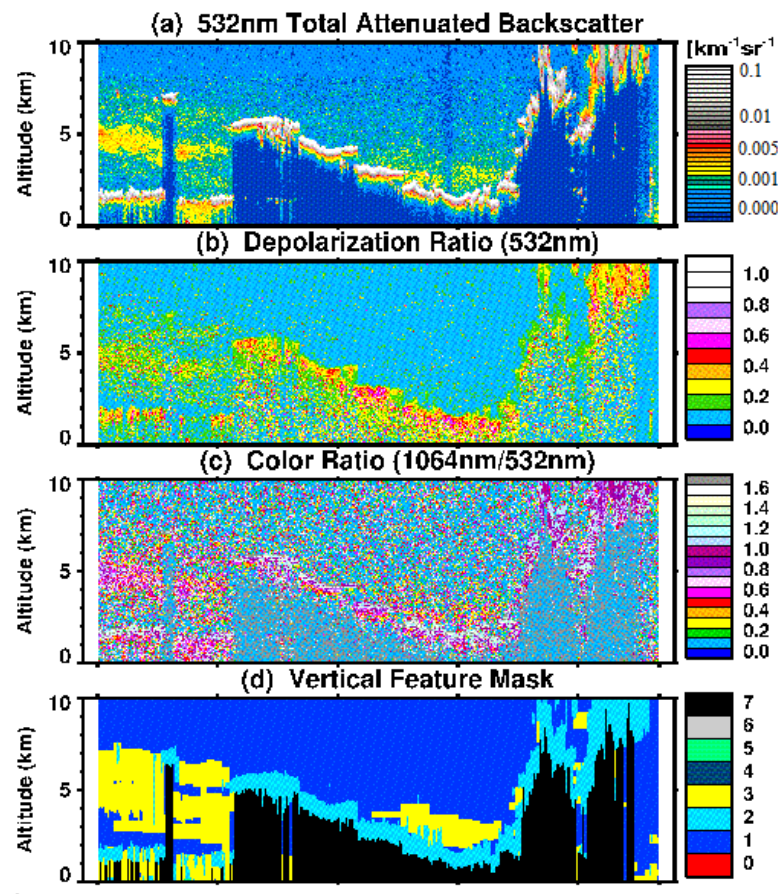

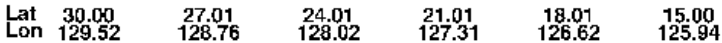

Figure 4. CALIPSO observations of dust on 25 April 2009. Dust at about $2 \mathrm{~km}$ appears in the north of Taiwan. In the bottom panel, where VFM (Vertical Feature Mask) of yellow indicating dust nature.

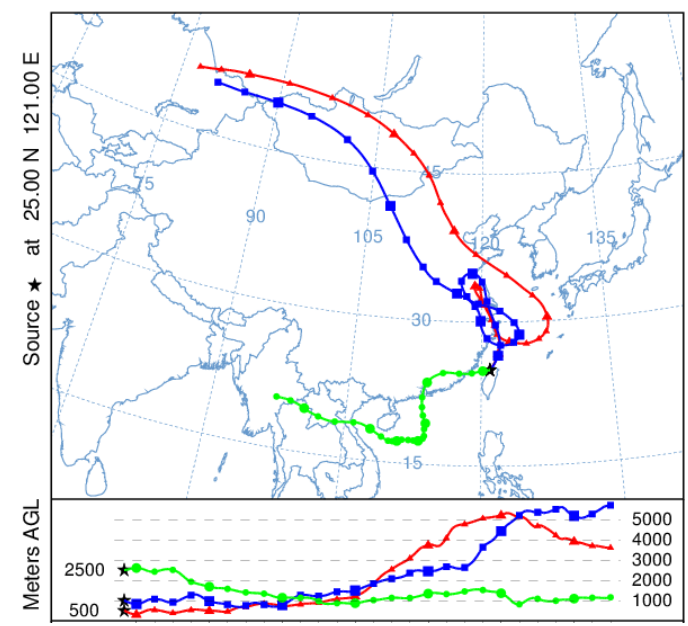

Figure 5. The backtrajectories of 2009-04-25 at 500, 1000, $2500 \mathrm{~m}$ with sources of northern and southern pollutants arrived to Taiwan area.

Lidar polarization measurements can be used to understand the dust-cloud processes by using the depolarization ratio which is zero for water vapour droplets but non-zero for irregular particles. Figure 6 shows a dust event occurred on 14 March 2009. Polarization and Raman lidar were both used to measure the dust and water vapor in the air. Figure 6 shows lidar signals of the parallel and perpendicular polarization channels on 14 March 2009. The lower two panels are the polarization measurements and the top panel is the Raman water vapor signals. 


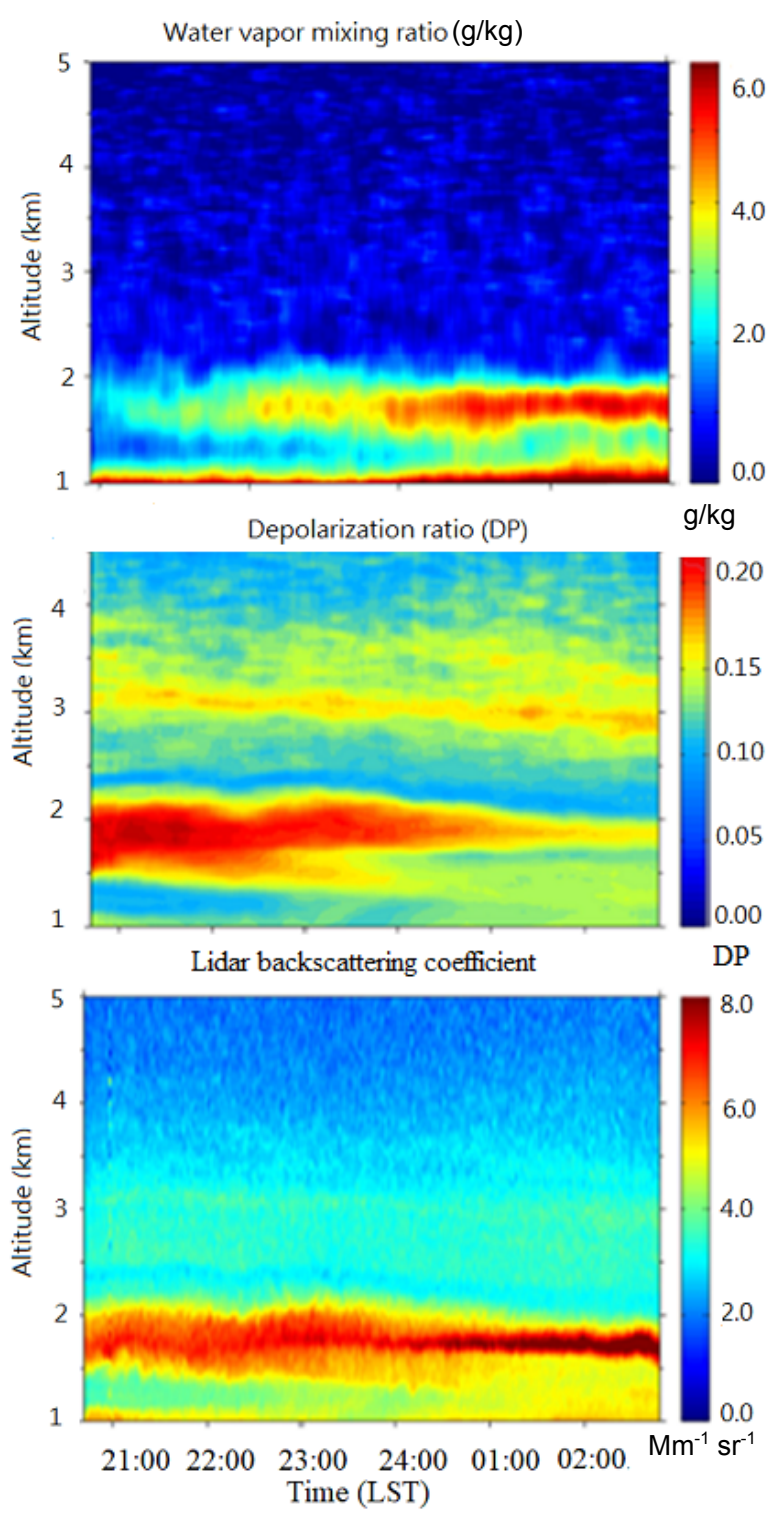

Figure 6. The lower and middle panels are the parallel polarization channel in unit of BR (backscattering ratio: $\mathrm{Mm}^{-1} \mathrm{sr}^{-1}$ ) and DP (depolarization ratio). The top is the Raman water vapor $(\mathrm{g} / \mathrm{kg})$. Dust layers found at 2 and $3 \mathrm{~km}$ and water vapor at 1 and $2 \mathrm{~km}$. As shown in the figure, the $2 \mathrm{~km}$ water vapor was initially weak and became strong toward the end, while the perpendicular channel shows decrease toward the end accompanying the increase of water vapour. At $3 \mathrm{~km}$, there is no water vapor and the depolarization properties stay the same.

The dust layer at about $2 \mathrm{~km}$ can be seen in both the parallel and perpendicular polarization channels. An increase of the signals of parallel channel indicates the enhancement of the dusty layer with backscattering ratio increases by almost a factor of two. The perpendicular polarization, or depolarization ratio, shows a decrease of intensity toward the end with the depolarization ratio $\delta$ changed from 0.2 initially to about 0.1 at the end. In the top, we find an increase of water vapor at about the same height as measured by a Raman lidar. Clearly, as the water vapor cloud was enhanced, it interacted with dust particles producing round droplets with reduced depolarization ratio. The process of changing particle shapes by absorbing water vapor lasted for about a few hours in real time.

\section{Summary}

Asian dust and various aerosols are important pollutants in East Asia affecting the environment and climate significantly but difficult to characterize. In the past, our group has carried out lidar measurements for measuring dust and aerosols at a site distant from the dust sources. Lidar is useful in providing the short and long-term measurements about the physical and optical parameters. These combined with other techniques of ground-based, satellite, models, etc. can provide many interesting observations as shown in this paper. Continuing efforts by using lidar, various types of instruments, and models should proceed to enhance our knowledge about properties of aerosols and effects on the climate.

\section{References}

1. P.B. Russell, R.W. Bergstrom, Y. Shinozuka, Y. Clarke, A.D. DeCarlo, P.F. Jimenez, J.L. Livingston, J. Redemann, O. Dubovik, A. Strawa, Atmos. Chem. Phys. 10, 1155-1169 (2010)

2. P.B. Russell, M. Kacenelenbogen, J.M. Livingston, O.P. Hasekamp, S.P. Burton, G.L. Schuster, M.S. Johnson, K.D. Knobelspiesse, J. Redemann, S. Ramachandran, B. Holben, J. Geophys. Res. Atmos. 119, 9838-9863 (2014)

3. R.W. Bergstrom, P. Pilewskie, P.-B. Russell, J. Redemann, T.C. Bond, P.K. Quinn, B. Sierau, Atmos. Chem. Phys. 7, 5937-5943 (2007)

4. A.R. Cazorla, K.J. Bahadur, J.F. Suski, D. Cahill, B. Chand, V. Schmid, V. Ramanathan, K.A. Prather, Atmos. Chem. Phys. 13, 9337-9350 (2013)

5. C. Deng, G. Zhuang, K. Huang, J. Li, R. Zhang, Q. Wan, Atmos. Chem. Phys. 11, 7319-7332 (2014)

6. W.J. Li, L.Y. Shao. Atmos. Chem. Phys. 9, 18631871 (2009)

7. Z. Huang, J.B. Nee, C.W. Chiang, S. Zhang, H. Jin, W Wang, T. Zhou, Remote Sens. 10, 1017 (2018)

8. J.B. Nee, C.W. Chiang, H. Hu, S. Hu, J. Yu, J. Geophys. Res. 112, D15202 (2007)

9. A.Laskin, M.J. Iedema, A. Ichkovich, E.R. Graber, I. Taraniuk, Y. Rudich, Faraday Discuss. 130, 453-468 (2005)

10. Y. Tobo, D. Zhang, A. Matsuki, Y. Iwasaka, Proc. Natl. Acad. Sci. 107, 17905-17910 (2010)

11. J. Li and K. Osada, J. Meteorol. Soc. Jpn. 85, 137149 (2007)

12. K. Okada, J. Heintzenberg, K. Kai, Y. Qin, Geophys. Res. Lett. 28, 3123-3126 (2001) 